\title{
Scintigraphic validation of a magnetic resonance imaging method to study gastric emptying of a solid meal in humans
}

\author{
C Feinle, P Kunz, P Boesiger, M Fried, W Schwizer
}

\begin{abstract}
Background-We have previously used a magnetic resonance imaging (MRI) method to study gastric emptying of liquids. So far, however, it has not possible to assess solid gastric emptying with this technique.

Aims-To validate scintigraphically MRI as a method for measuring emptying of a mixed solid/liquid meal.

Methods-In eight healthy subjects, gastric emptying of a solid/liquid (SM) and a liquid meal (LM) of identical energy content and macronutrient composition was studied by scintigraphy and MRI for 120 minutes.

Results-MRI and scintigraphy agreed with respect to emptying profiles (intraclass correlation coefficient $\left(R_{\mathrm{I}}\right)_{\mathrm{SM}}: \mathbf{0 . 9 8 8}$, $\left.R_{\mathrm{I}, \mathrm{LM}}: 0.917\right), \mathrm{t}_{1 / 2}\left(\mathrm{SM}_{\mathrm{MRI}}: 129(9), \mathrm{SM}_{\mathrm{Scinti}}: 123\right.$ (11) minutes, NS; $\mathbf{L} M_{M R I}: 100$ (7), $\mathbf{L} M_{\text {Scinti: }}$ : 110 (8) minutes, NS) and AUC (SM MRI 8999 (232), SM $_{\text {Scinti }}: 8788$ (277) $\mathrm{min} \%, \mathrm{NS}$; $\mathbf{L M}_{\mathrm{MRI}}$ : 8819 (368), $\mathbf{L M}_{\mathrm{Scinti}}: 8891$ (321) $\min \%$, NS).

Conclusions-MRI can be used to measure reliably gastric emptying not only of liquid but also of mixed solid/liquid meals in humans.

(Gut 1999;44:106-111)
\end{abstract}

Keywords: magnetic resonance imaging; scintigraphy; gastric emptying; solid meal; liquid meal

Department of Internal Medicine, Division of Gastroenterology, University Hospital Zürich, Switzerland

C Feinle

$M$ Fried

W Schwizer

Institute of Biomedical Engineering and

Medical Informatics,

University/ETH

Zürich, Switzerland

P Kunz

P Boesiger

Correspondence to: Dr C Feinle, Department of Internal Medicine, Division of Gastroenterology,

University Hospital Zürich, Rämistr. 100, 8091 Zürich,

Switzerland.

Accepted for publication 7 July 1998
A variety of methods, including scintigraphy, ${ }^{1}$ ultrasonography, ${ }^{3}$ and intubation techniques, ${ }^{4}$ have been used to assess gastric emptying in both the clinical and research settings. Each of these methods suffers from disadvantages, including exposure of the subjects to radiation during scintigraphy, difficulty in measuring proximal and distal gastric regions simultaneously by ultrasonography, and the possible disturbances of normal physiology induced by gastrointestinal intubation.

Recently, we have developed and validated a magnetic resonance imaging (MRI) technique to measure gastric emptying of liquid nutrient meals with a high image acquisition frequency, ${ }^{5}$ enabling us to monitor gastric emptying and motility simultaneously. ${ }^{6}$

Thus far, however, only the emptying of liquid meals has been studied with the MRI technique. For the evaluation of clinically relevant gastric emptying disorders, it is essential to be able to investigate the emptying of solids, particularly in conditions where emptying of the solid phase is disturbed, but emptying of the liquid phase is less affected or normal, as is frequently the case in patients with motilitylike functional dyspepsia. ${ }^{78}$

Using scintigraphy as a gold standard, the aims of this study were to validate an MRI technique for measurement of the gastric emptying of a solid meal and to develop suitable solid and liquid test meals of identical macronutrient composition and energy content for use during MRI.

\section{Methods}

SUBJECTS

Experiments were performed on eight healthy volunteers (four men and four women), aged 23-42 years. The subjects were non-smokers, of normal weight for height with a body mass index of 22.1 (1.4 SD), were not taking any regular medication, and had no history of gastrointestinal disease or abdominal surgery. All subjects gave informed written consent to take part in the study, which was carried out with the approval of the Ethics Committee of the Department of Internal Medicine at the University Hospital Zürich.

\section{STUDY PROTOCOL}

Each subject was studied on four occasions, separated by at least one week. Two test meals, a liquid, and a mixed solid/liquid meal (subsequently referred to as "solid meal") were used. Gastric emptying of each meal was studied scintigraphically on one occasion and by MRI on another. The order of the test meals was randomised, but for technical reasons, the order of the different techniques could not be randomised. MRI studies were performed prior to scintigraphic studies, and all data were analysed following completion of the entire study.

Scintigraphic studies commenced at 900 am, following an overnight fast; MRI studies commenced at $100 \mathrm{pm}$, after a five hour fast. For logistic reasons (access to the machines), scintigraphic studies could only be carried out in the morning, whereas the MRI studies could only be performed in the afternoon.

Measurement of gastric emptying of either the solid or the liquid meal commenced immediately after ingestion of the meal and continued for two hours. All studies were standardised to

Abbreviations used in this paper: MRI, magnetic resonance imaging; Gd-DOTA, gadolinium tetraazacyclododecane tetraacetic acid; AUC, area under the curve; $R_{1}$, intraclass correlation coefficient. 

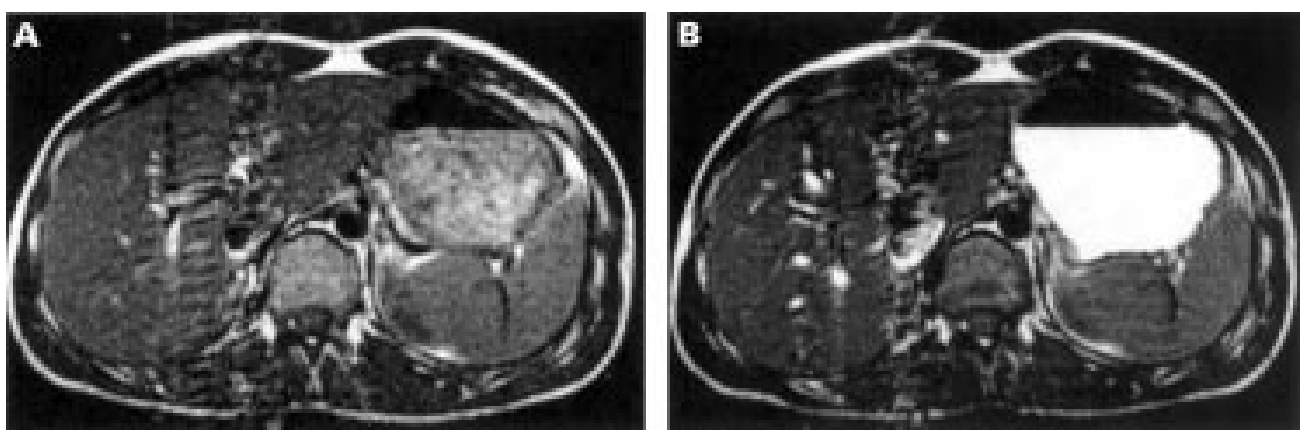

Figure 1 Assessment of intragastric volume by MRI. Images obtained after ingestion of the solid ( $A$ ) and the liquid (B) meal. Gastric contents are clearly visible on both images. With the liquid meal, contrast between gastric contents and surrounding tissues was enhanced by addition of the marker Gd-DOTA.

be performed with the subjects in the supine position because of the requirements for positioning in the MRI machine.

\section{TEST MEALS}

The liquid test meal consisted of a mixture of enteral and parenteral feeding solutions (154 ml Carbospare (Abbott AG, Cham, Switzerland), $264 \mathrm{ml} \mathrm{10 \%} \mathrm{Intralipid} \mathrm{(Pharmacia} \mathrm{AG,}$ Dübendorf, Switzerland)), $10 \mathrm{~g}$ albumin, and $26 \mathrm{ml}$ water.

The solid test meal was a pancake, prepared from $108 \mathrm{~g}$ eggs, $98 \mathrm{~g}$ potatoes, $44 \mathrm{~g}$ bacon, and $5 \mathrm{~g}$ butter, and was served with $200 \mathrm{ml}$ water.

The test meals were of identical energy content $(2.19 \mathrm{MJ})$, weight (455 g), and macronutrient composition ( $73 \%$ energy from fat, $12 \%$ from carbohydrates, $15 \%$ from protein).

ASSESSMENT OF GASTRIC EMPTYING

MRI technique

The liquid meal was labelled with $600 \mu \mathrm{M}$ Gd-DOTA (gadolinium tetraazacyclododecane tetraacetic acid; Dotarem, Laboratoire Guerbet, Aulnay-sous-Bois, France) to obtain good contrast between the stomach contents and surrounding tissues. The solid meal gave satisfactory contrast without addition of GdDOTA (fig 1). After ingestion of one of the test meals, subjects were immediately placed in the MRI scanner (1.5 Tesla, Philips Gyroscan ACS NT, Philips Medical Systems, Best, The Netherlands), and a transverse scan ("volume scan") was performed to assess intragastric volume. A multislice turbospin echo technique was used to acquire 28 slices (slice thickness: $7.5 \mathrm{~mm}$ ) over 60 seconds (echo time (TE): 40 $\mathrm{ms}$, repetition time (TR): $526 \mathrm{~ms}$ ). The spatial resolution of these scans was $1.6 \mathrm{~mm}$ (field of view: $420 \times 420 \mathrm{~mm}$, scan matrix: $256 \times 256$ voxels). Volume scans were repeated at 15 minute intervals for the duration of the study.

Gastric meal volume was corrected for progressive dilution due to gastric secretion. A phantom experiment was performed prior to the study to determine the relation between dilution of gastric content by gastric secretion and signal intensity for both the solid and the liquid meal. Small bottles were filled with defined quantities of either the liquid or the solid test meal and mixed with increasing quantities of $0.01 \mathrm{M}$ hydrochloric acid. The bottles were then imaged simultaneously in a single plane. MRI parameters were adjusted to obtain a defined correlation between the concentration of gastric secretion and image intensity. With the liquid meal, an exponential correlation was found between the concentration of hydrochloric acid and the signal intensity. With the solid meal, a linear correlation was obtained. During gastric emptying studies, an external standard, consisting of a cylindrical polyethylene tube containing either the solid or the liquid meal, was placed beside the subjects and imaged simultaneously. The image intensity of the tube content served as a reference to correct for gastric secretion. The relation between mean intensity of the external standard, and mean intensity of gastric content and secretion as obtained from the in vitro experiments was then used to correct total gastric volumes for gastric secretion. An increase in gastric secretion resulted in a decrease in signal intensity of gastric contents.

To reduce motion artefacts during scans, volume scans were broken up into four packages of 15 seconds duration each, separated by five seconds; subjects were asked to hold their breath in expiration during scans, but were allowed to breathe between consecutive scans.

\section{Scintigraphy}

The solid meal was labelled with $500 \mu \mathrm{Ci}(18.5$ $\mathrm{MBq})^{99 \mathrm{~m}} \mathrm{Tc}$-sulphur colloid (bound to the egg yolk, which was thoroughly mixed with the other ingredients before cooking); the water component of the meal was labelled with 60 $\mu \mathrm{Ci}(2.4 \mathrm{MBq}){ }^{111} \mathrm{In}-\mathrm{DTPA}$. The liquid test meal was labelled with $500 \mu \mathrm{Ci}(18.5 \mathrm{MBq})$ ${ }^{99 \mathrm{~m}}$ Tc-DTPA. A cobalt marker was positioned on the sternum, sufficiently high above the stomach so as not to interfere with the signals emitted by the meal markers, and kept in place throughout the entire study. This marker was used as a reference to correct the images for movement of the subjects during the study. Immediately after meal ingestion, the subjects were positioned under the collimator of the gamma camera, and images of the distribution of radioactivity in the stomach were collected over one minute periods for a total of $120 \mathrm{~min}$ utes. In the case of the solid meal, which was labelled with two isotopes, two series of images were acquired simultaneously, one for the solid phase and the other for the water phase of the meal. At the end of the study, the subjects drank $150 \mathrm{ml}$ water radiolabelled with $30 \mu \mathrm{Ci}$ 
Table 1 Half times ( $t_{1 / 2}$ ) of emptying and areas under the emptying profiles (AUC) for the solid and liquid meals as assessed by magnetic resonance imaging (MRI) and scintigraphy

\begin{tabular}{|c|c|c|c|c|}
\hline & \multicolumn{2}{|l|}{ Solid meal } & \multicolumn{2}{|l|}{ Liquid meal } \\
\hline & $M R I$ & Scintigraphy & $M R I$ & Scintigraphy \\
\hline$t_{1 / 2}(\min )$ & $129(9)$ & $123(11)$ & $100(7)^{\star}$ & $110(8)$ \\
\hline AUC (min \%) & 8999 (232) & 8788 (277) & 8819 (368) & $8891(321)$ \\
\hline
\end{tabular}

Results are expressed as mean (SEM).

$\star$ Significantly different from the solid meal $(M R I), \mathrm{p}<0.05$.

(1.2 MBq) ${ }^{111} \mathrm{In}-\mathrm{DTPA}$, and a left lateral image of the stomach was obtained over five minutes to correct for the changing attenuation of the gamma emissions due to the anatomical position of the stomach. ${ }^{2}$

In vitro stability of the solid phase labelling with ${ }^{99 m}$ Tc-sulphur colloid

Defined quantities of the omelette were repeatedly incubated with gastric juice at $\mathrm{pH} 2$ and $\mathrm{pH} 4$ for 20 minutes, centrifuged, and the supernatant discarded. After five incubation cycles, ${ }^{99 \mathrm{~m}} \mathrm{Tc}$ counts were determined in the sediment; they amounted to $89 \%$ and $79 \%$ of counts present in the meal samples before incubation at $\mathrm{pH} 2$ and $\mathrm{pH} 4$, respectively.

Attenuation coefficients for Tc and In

These were determined in order to account for signal attenuation by body tissue. For this purpose, either the ${ }^{99 \mathrm{~m}} \mathrm{Tc}$ or the ${ }^{111} \mathrm{In}$ source was positioned behind acrylic glass. Radioactive counts in a defined region of interest around the respective source were acquired for distances between sources and the collimator of $0-13 \mathrm{~cm}$ and corrected for background radiation. The mass attenuation coefficients $\mu$, calculated according to the exponential attenuation law for both ${ }^{99 \mathrm{~m}} \mathrm{Tc}$ and ${ }^{111} \mathrm{In}$, were $\mu^{\prime}=$ $0.131 \mathrm{~cm}^{2} / \mathrm{g}$ for ${ }^{99 \mathrm{~m}} \mathrm{Tc}$ and $\mu^{\prime}=0.113 \mathrm{~cm}^{2} / \mathrm{g}$ for ${ }^{111}$ In. Linear attenuation coefficients, $\mu\left(\mathrm{cm}^{-1}\right)$ for human tissue, obtained by using the density of water as an approximation to the density of human tissue, were therefore $\mu=0.131 \mathrm{~cm}^{-1}$ for ${ }^{99 \mathrm{~m}} \mathrm{Tc}$ and $\mu=0.113 \mathrm{~cm}^{-1}$ for ${ }^{111} \mathrm{In}$.

DATA ANALYSIS

MRI data

Gastric areas of interest for each slice were identified by a distinct positive contrast against the surrounding tissues and outlined on the screen. The volume of gastric contents was then determined by multiplying the sum of these areas by the slice thickness. Gastric meal volume was calculated by taking into account gastric secretion, using the external standard. ${ }^{5}$ Values for meal volume remaining in the stomach at 15 minute intervals were fitted to a power exponential model, ${ }^{9}$ and the half time of emptying $\left(t_{1 / 2}\right)$ from the whole stomach and the areas under the curve of the emptying profiles (AUC) of the whole stomach as well as proximal and distal gastric subareas were determined. Proximal and distal gastric regions were identified from three dimensional reconstructions of the stomach and divided at the angula. To obtain the relative distribution of the solid and the liquid test meal in the proximal and the distal stomach over the course of the study (120 minutes), volumes in each
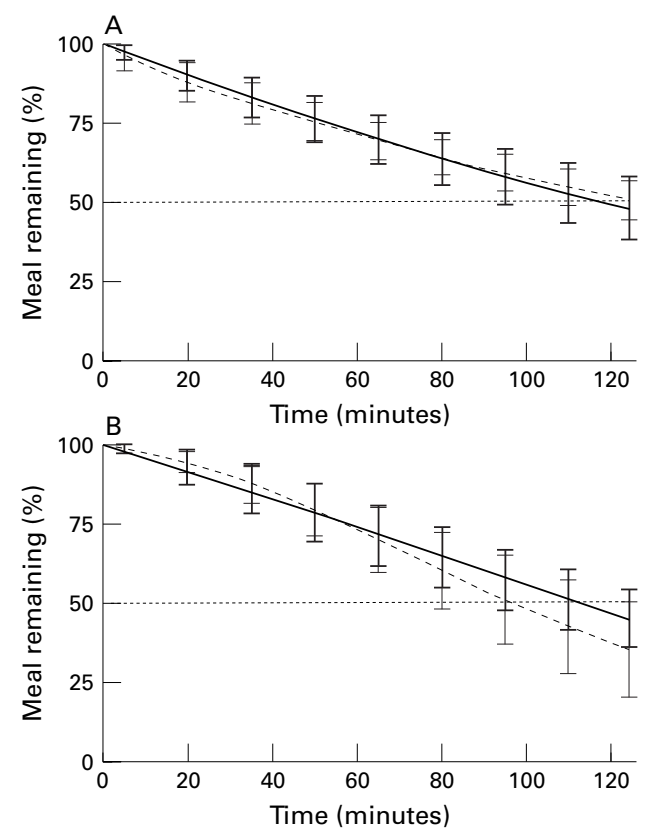

Figure 2 Gastric emptying profiles for the $(A)$ solid and (B) liquid meals as obtained by MRI (dotted line) and scintigraphy (solid line). Data are means (of the fitted curves) (SEM).

subarea were expressed as percentages of total gastric volume (equalling 100\%) as obtained every 15 minutes, and a mean calculated.

\section{Scintigraphic data}

The position of the stomach was identified on the screen and a region of interest outlined. The proximal and distal regions of the stomach were defined visually as two regions of intense radioactivity separated by a fainter band of radioactivity coinciding with the angula. Counts from each region of interest were corrected for isotope decay and tissue attenuation, expressed as percentage of counts obtained immediately after meal ingestion, fitted to a power exponential model as already described for the MRI data, and then used to plot profiles to describe meal emptying from the whole stomach and from the two subareas. The time from the onset of emptying to the point at which $50 \%$ of the isotope had left the stomach $\left(t_{1 / 2}\right)$ was obtained for whole stomach emptying, and the AUC for the emptying from the whole stomach as well as proximal and distal gastric subareas. The relative distribution of the solid and the liquid test meal in the proximal and the distal stomach over 120 minutes was determined by expressing the radioactive counts in each subarea as percentages of radioactive counts in the whole stomach (equalling $100 \%$ ) at a certain time point. The mean was then calculated to obtain the average intragastric distribution of the meals in each gastric region over 120 minutes.

\section{STATISTICAL ANALYSIS}

Agreement between the data obtained by the scintigraphic and the MRI method was assessed by calculating the intraclass correlation $\left(\mathrm{R}_{\mathrm{I}}\right)$ as described previously. ${ }^{10}$ According to this test, two methods show agreement if the lower 
Table 2 Intragastric distribution of the solid and liquid test meals

\begin{tabular}{lll}
\hline & Proximal stomach & Distal stomach \\
\hline Solid meal & & \\
$\quad$ Scintigraphy & $78.6(4.8)^{\star} \dagger$ & $21.4(1.7)^{\star} \dagger$ \\
$\quad$ MRI & $90.5(3.1)^{\star}$ & $9.5(1.1)^{\star}$ \\
Liquid meal & & \\
$\quad$ Scintigraphy & $91.2(0.8) \dagger$ & $8.8(0.8) \dagger$ \\
$\quad$ MRI & $94.9(3.6)$ & $5.1(1.3)$
\end{tabular}

Results are expressed as mean (SEM).

For scintigraphic data, percentages of the radioactive counts in the whole stomach are shown. Magnetic resonance imaging (MRI) data are percentages of the volume of the total gastric contents.

* Significantly different from the respective liquid meal data; tsignificantly different from the respective MRI data, $p<0.05$.

limit of the $95 \%$ confidence interval of the intraclass correlation is at least 0.75 and the difference between the means obtained from the two methods is not statistically significant, i.e. $p>0.05$.

To assess possible group differences between methods and/or meals, data (emptying profiles, $t_{1 / 2}$, AUC) were analysed using repeated measures analysis of variance with time and meal type as cofactors. Data are expressed as means (SEM), and probability values of $\mathrm{p}<0.05$ were regarded as statistically significant.

\section{Results}

AGREEMENT BETWEEN MRI AND SCINTIGRAPHY Emptying from the whole stomach

Very good agreement was obtained between MRI and scintigraphy for both meals considering the emptying profiles $\left(\mathrm{R}_{\mathrm{I} \text {, solids }}: 0.988, \mathrm{R}_{\mathrm{I} \text {, liquids }}\right.$ : 0.917 ) (fig 2). Moreover, no differences existed between the two methods for $t_{1 / 2}$ and AUC (table 1).

Intragastric meal distribution

Both MRI and scintigraphy showed that significantly smaller quantities of food remained in the proximal stomach following ingestion of the solid meal as compared with the liquid meal, and that significantly greater quantities of the solid meal than of the liquid meal were present in the distal stomach as assessed by AUC (table 2). In addition, greater amounts of both solid and liquid meal were observed in the distal stomach when assessed by scintigraphy as compared with MRI. The opposite was true for the proximal stomach. This was very likely due to an overlap of distal stomach and duodenum overestimating distal gastric content during scintigraphy (fig 3 ), as observed in $5 / 8$ subjects with the solid meal, and in $7 / 8$ subjects with the liquid meal.

DIFFERENCES IN GASTRIC EMPTYING BETWEEN

THE LIQUID AND THE SOLID MEAL

Scintigraphy

No differences were found between emptying of the liquid and the solid test meal, in terms of emptying profiles, $\mathrm{t}_{1 / 2}$, or AUC (table 1 ).

$M R I$

Overall, there were no differences between emptying of the liquid and the solid meal. However, there was a significant interaction with time for the emptying profiles: gastric
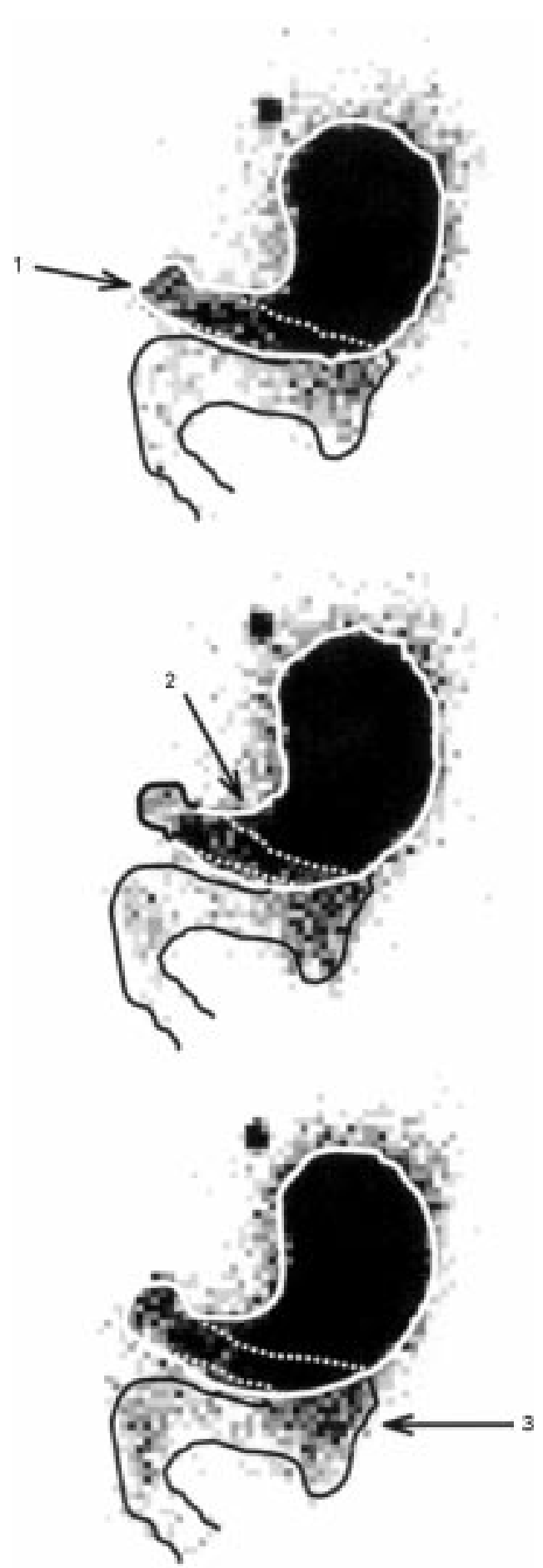

Figure 3 Demonstration of the overlap between gastric and duodenal contents during scintigraphy. As gastric contents are emptied (1), they move along a loop of intestine in front of or behind the stomach (2), and "leave" the stomach in the region of the greater curvature (3).

emptying of the liquid meal was significantly faster than emptying of the solid meal between 95 and 120 minutes postprandially. This was also reflected by the difference in $\mathrm{t}_{1 / 2}$, but not the AUC (table 1).

Discussion

The main finding of this study is that MRI is a valuable technique in the study of gastric emptying of a mixed solid and liquid meal. We have 
validated this technique previously for the investigation of liquid meal emptying ${ }^{5}$; however, in order to apply this technique to clinical practice and for research purposes, it is essential to have a means of measuring gastric emptying of solids. ${ }^{7}{ }^{8} \mathrm{We}$ found excellent agreement between MRI and scintigraphy for both the liquid and the mixed solid/liquid meal when comparing emptying profiles, indicating our MRI technique to be a valid tool to study gastric emptying. Moreover, there were no differences in half times of gastric emptying and areas under the curves between the two methods for the respective meals.

These results have significant implications for the use of MRI in clinical practice and as a research tool. The clinical relevance lies in the ability to detect and study gastric emptying disorders affecting the solid component of a meal which may not be appreciated if only emptying of the liquid phase were to be examined. The importance of this is emphasised by the fact that quite a number of patients have disturbed emptying of solids, while emptying of liquids is normal. ${ }^{7811}$ Other methods used to study gastric emptying have distinct disadvantages when compared with MRI: scintigraphy involves significant radiation exposure; with ultrasonography it may be difficult to measure proximal and distal gastric regions simultaneously, and gastric secretion cannot be accounted for $^{312}$; the use of applied potential tomography is limited by technical shortcomings ${ }^{13}$; and invasive intubation techniques are unpleasant and may disturb normal physiology. ${ }^{4}$

The importance of MRI as a research tool lies in the continuing need to clarify further the mechanisms involved in the processes that regulate gastric solid and liquid emptying. In contrast to liquids, solid food requires trituration prior to passage into the intestine. ${ }^{14}$ In this context it is important to note that using MRI it is possible to study gastric emptying and contractile activity simultaneously, ${ }^{6}$ and therefore to assess the motor mechanisms involved in gastric emptying. Detailed understanding of the factors controlling gastric solid and liquid emptying would in turn have clinical implications and may point to specific targets for drug therapy of disordered gastric emptying.

We also compared gastric emptying of the liquid and the mixed solid/liquid test meals. Except for their differing physical properties, the meals were of identical macronutrient composition, energy content, and weight. Frequently, solid and liquid meals used in gastric emptying studies show great variation with regard to their composition, and hence, are not directly comparable. Gastric emptying of solid meals is generally considered to be slower than emptying of liquid meals ${ }^{1516}$ due to the grinding processes necessary with the solid meal. However, this notion is based on studies employing liquid and solid meals of great differences with regard to their composition, energy content, and physical properties. Studies utilising meals of similar macronutrient composition, but varying viscosity or particle size have not yielded clear cut results. ${ }^{17-20}$ Gas- tric emptying of the low viscosity or small particle test meals was either faster than ${ }^{17} 1820$ or not different ${ }^{19}$ from the emptying of high viscosity or large particle meals. In our study, the liquid and the solid meal were standardised regarding their nutrient composition but varied in their physical properties and yet emptied with a similar pattern. In contrast to most other studies, our test meals were probably of a higher energy and fat content which may have independently slowed gastric emptying. This concept is supported by the observation that the half time of emptying tended to be shorter for the liquid meal than for the solid meal, although this difference was not statistically significant. Although the effects of some of these variables may be different in the supine position to the sitting position, we have previously shown that the MRI technique can detect differences in gastric emptying between meals of different energy content and after pharmacological manipulation. ${ }^{62}$

It is, however, conceivable that an initially fast emptying of the liquid meal (immediately after meal ingestion) could have led to early feedback inhibition from duodenal chemoreceptors, effectively slowing emptying of the liquid meal. The subsequent change of position by our subjects from upright to supine may then have helped to slow down the emptying of the liquid meal, as this meal may, due to its relatively low viscosity, have been redistributed into the proximal stomach more readily than the solid meal. This would also be consistent with our observation of the intragastric distribution of the two test meals in that significantly greater quantities of the solid than of the liquid meal were present in the distal stomach.

Although there were no overall differences between solid and liquid meal emptying with MRI, statistical analysis revealed an interaction with time over the last 30 minutes of the study. This was also reflected in a lower half time of emptying of the liquid meal. With scintigraphy, however, no differences existed in the half times of emptying between the solid and the liquid meal. The different results obtained from the two methods could be due to the variation of data between study days, as it has been shown that large variations exist with this parameter not only between, but also within subjects. ${ }^{1}$ On the other hand, the lack of a difference between the solid and the liquid meal with the scintigraphic technique could point towards a methodological explanation. There is good evidence from our scintigraphic images (fig 3) of an overlap of the stomach and the proximal duodenum in the majority of subjects. Scintigraphy is a projection method, and therefore, a distinction between the stomach and any other part of the intestine situated in front of or behind the stomach and containing radiolabelled chyme is impossible. As a result, scintigraphy may falsely overestimate the quantity of gastric contents. With MRI, this cannot occur, as the silhouette of gastric contents is identified in three dimensions. We did not set out to study this phenomenon, and were therefore not able to quantify the extent of this overlap. 
The scintigraphic images, however, clearly show the occurrence of an overlap, as shown in fig 3.

In summary, our data show that it is feasible to utilise MRI as a diagnostic as well as a research tool to study gastric emptying not only of liquids, but also of mixed solid/liquid meals. Moreover, MRI has some important advantages over scintigraphy. With MRI, only the organ of interest is studied, whereas with scintigraphy, it is not possible to identify any overlap that may occur between radioactive contents of the stomach and the proximal duodenum. Moreover, MRI is a non-invasive technique which does not involve any exposure of the subjects to radiation.

The authors are grateful to Kamillo-Eisner-Stiftung for their generous financial support and to Dr Geoff Hebbard for
reviewing the manuscript. Extracts of this work have previously reviewing the manuscript. Extracts of this work have previously
been published in abstract form (Gastroenterology 1996;110: A662; Gastroenterology 1997;114:A730).

1 Collins PJ, Horowitz M, Cook DJ, et al. Gastric emptying in normal subjects - a reproducible technique using a single scintillation camera and computer system. Gut $1983 ; 24: 1117-25$

2 Collins PJ, Horowitz M, Shearman DJC, et al. Correction for tissue attenuation in radionuclide gastric emptying studies: a comparison of a lateral image method and a geometric mean method. Br f Radiol 1984;57:689-95.

3 Holt S, Cervantes J, Wilkinson AA, et al. Measurement of gastric emptying rate in humans by real-time ultrasound. Gastroenterology 1986;90:918-23.

4 Read NW, Al Janabi MN, Bates TE, et al. Effect of gastrointestinal intubation on the passage of a solid meal through the stomach and small intestine in humans. Gastroenterology 1983;84:1568-72.
5 Schwizer W, Maecke H, Fried M. Measurement of gastric emptying by magnetic resonance imaging in humans. Gasemptying by magnetic resonan

6 troenterology 1992;103:369-76. proximal and distal gastric motility with magnetic resonance imaging. Am f Physiol 1996;271:G217-22.

7 Jian R, Ducrot F, Ruskone A, et al. Symptomatic, radionuclide and therapeutic assessment of chronic idiopathic dyspepsia. Dig Dis Sci 1989;34:657-64.

8 Urbain JLC, Vekemans MC, Parkman H, et al. Dynamic antral scintigraphy to characterize gastric antral motility in functional dyspepsia. $\mathcal{F}$ Nucl Med 1995;36:1579-86.

9 Elashoff JD, Reedy TJ, Meyer JH. Analysis of gastric emptying data. Gastroenterology 1982;83:1306-12.

10 Lee J, Koh D, Ong CN. Statistical evaluation of agreement between two methods for measuring a quantitative variable. Comput Biol Med 1989;19:61-70.

11 Scott AM, Kellow JE, Shuter B, et al. Intragastric distribution and gastric emptying of solids and liquids in functional dyspepsia. Dig Dis Sci 1993;38:2247-54.

12 Mamtora H, Thompson D. Gastric ultrasound. In: Read NW, ed. Gastrointestinal motility: which test? Petersfield: Wrightson Biomedical Publishing, 1989:99-103.

13 Avill R, Mangnall YF, Bird NC, et al. Applied potential tomography: a non-invasive technique for measuring gastric emptying. Gastroenterology 1987;92:1019-26.

14 Meyer J. Gastric emptying of ordinary food: effect of antrum on particle size. Am $\mathcal{F}$ Physiol 1980;239:G133-5.

15 Hinder RA, Kelly KA. Canine gastric emptying of solids and liquids. Am f Physiol 1977;233:E335-40.

16 Kelly KA. Gastric emptying of liquids and solids: roles of proximal and distal stomach. Am F Physiol 1980;239:G71proxis

17 Ehrlein, H-J, Pröve J. Effect of viscosity of test meals on gastric emptying in dogs. Q $\mathcal{F}$ Exp Physiol 1982;67:419-25.

18 Holt S, Reid J, Taylor TV, et al. Gastric emptying of solids in Holt S, Reid J, Taylor TV,
man. Gut 1982;23:292-6.

19 Houghton LA, Hickson F, Read NW. Effect of food consistency on gastric emptying in man. Gut 1987;28:1584-8.

20 Urbain JLC, Siegel JA, Charkes ND, et al. The twocomponent stomach: effects of meal particle size on fundal and antral emptying. Eur $\mathcal{F} \mathrm{Nucl} \mathrm{Med} \mathrm{1989;15:254-9.}$

21 Schwizer W, Borovicka J, Kunz P, et al. Role of cholecystokinin in the regulation of liquid gastric emptying and gastric motility in humans: studies with the CCK antagonist loxiglumide. Gut 1997;41:500-4. 